\title{
Subarachnoid and epidural dexmedetomidine for the prevention of post-anesthetic shivering: a meta-analysis and systematic review
}

This article was published in the following Dove Press journal:

Drug Design, Development and Therapy

Yi-Zheng Li $\mathbb{D}^{1,2}$
Yi Jiang $\mathbb{D}^{2}$
Han Lin $\mathbb{D}^{1}$
Xue-Ping Yang $\mathbb{D}^{1}$

'Department of Anesthesiology and Perioperative Medicine, The Second Affiliated Hospital and Yuying Children's Hospital of Wenzhou Medical University, Wenzhou, Zhejiang, People's Republic of China; ${ }^{2}$ Department of Anesthesiology, Wenzhou Integrated Chinese and Western Hospital of Zhejiang Chinese Medical University, Wenzhou, Zhejiang, People's Republic of China
Correspondence: Han Lin

Department of Anesthesiology and Perioperative Medicine, The Second Affiliated Hospital and Yuying Children's Hospital of Wenzhou Medical University, 109 Western Xueyuan Road, Lucheng, Wenzhou, Zhejiang 325027, People's

Republic of China

Tel +86 I 58687 I 083।

Email nanlinhannansh@gmail.com
Background: Post-anesthetic shivering incurs discomfort to patients or even exacerbates their condition. However, no ideal drug has been well established for preventing postanesthetic shivering. Currently, subarachnoid and epidural dexmedetomidine have demonstrated to have an anti-shivering effect.

Methods: An electronic search was conducted to identify randomized placebo-controlled trials reporting shivering and then compared subarachnoid and epidural dexmedetomidine with placebo in adults undergoing selective surgery. Data assessment and pooling were analyzed by Review Manager 5.3, STATA 15.0 and GRADE-pro 3.6 software.

Results: Twenty-two studies (1389 patients) were subjected to this meta-analysis. The incidence of post-anesthetic shivering decreased from $20.10 \%$ in the placebo group to $10.30 \%$ in the dexmedetomidine group (RR, $0.48 ; 95 \% \mathrm{CI}, 0.39-0.59 ; Z=6.86, P<0.00001$, $I^{2}=32 \%$ ). Non-Indian, epidural-space route and cesarean subgroups indicated a better antishivering effect. In the subarachnoid-space route subgroup, a dosage of $>5 \mu \mathrm{g}$ showed significantly superior anti-shivering effects than that of $\leq 5 \mu \mathrm{g}$. Subarachnoid and epidural dexmedetomidine increased the incidence of bradycardia, had no impact on nausea and vomiting, shortened the onset of block and lengthened the duration of block and analgesia. However, its effect on hypotension and sedation remained uncertain. The overall risk of bias was relatively low. The level of evidence was high, and the recommendation of voting results was strong.

Conclusion: Dexmedetomidine as a subarachnoid and epidural adjunct drug could decrease the incidence of post-anesthetic shivering in a dose-dependent manner. However, caution should be taken in patients with original bradycardia.

Keywords: dexmedetomidine, shivering, meta-analysis, subarachnoid, epidural

\section{Introduction}

Post-anesthetic shivering (PAS), characterized by spontaneous skeletal muscular tremors due to cutaneous arteriovenous shunt vasoconstriction, has an incidence of about $53 \% .^{1}$ PAS initiates a hypothermia-hypermetabolism vicious cycle by further facilitating pain and wound infection and prolonging the length of hospitalization. ${ }^{2}$ Predisposed factors, including hypothermia, hypovolemia, blood loss, older age, female sex, and the level of anesthesia, can all promote PAS. $^{3-5}$

Although electromyography is sensitive in detecting PAS, but it is cumbersome and therefore not widely used. The Bedside Shivering Assessment Scale (BSAS) is 
used based on skeletal muscular tremors; however, it is rarely used during the perioperative period. ${ }^{6}$ Still, there is no currently available objective multidimensional index to detect or predict the occurrence of PAS. Keeping warm and pharmacological intervention are known as two major strategies against shivering, but some recent meta-analyses have shown that extra thermal insulation, including forced air and fluid warming, has no significant effect on PAS. ${ }^{7,8}$ Drugs such as meperidine are not recommended as a routine practice, owing to their serious adverse effects, unless the condition becomes uncontrollable. Therefore, a safer and more-effective drug for PAS is urgently required.

Dexmedetomidine (DEX) is a highly selective $\alpha-2$ receptor agonist used to reduce the shivering threshold and has proven to have a better anti-shivering effect than meperidine. $^{9-11}$ A meta-analysis by Hoffman et al. ${ }^{12}$ revealed that intravenous (IV) DEX was not an optimal choice against PAS because of cardiovascular adverse effects. Studies proving the safety of subarachnoid and epidural (S\&E) DEX have been reported in the USA and Japan. ${ }^{13-15}$ The advantages of S\&E DEX include prolonged analgesia and deepened sedation with tolerable adverse effects. Recently, some meta-analyses have indicated that S\&E DEX reduces the incidence of PAS; ${ }^{16,17}$ however, these meta-analyses enrolled non-randomized controlled trials (non-RCTs) and have confounding factors in intervention. Thus, it is difficult to explore whether S\&E DEX is propitious against PAS.

The chief goal of this meta-analysis was to assess the anti-shivering effect of prophylactic S\&E DEX versus placebo on PAS in patients undergoing selective operation with S\&E anesthesia. A supplemental objective of this study was to identify the side effects of prophylactic S\&E DEX.

\section{Methods}

This manuscript adheres to the applicable PRISMA statements. A protocol can be found at http://www.crd.york.ac.uk/ PROSPERO/display_record.asp?ID=CRD42016053006.

\section{Eligibility criteria}

Included criteria were: (1) RCTs; (2) adults older than 18 years who were categorized as ASA I-III and underwent selective surgery under spinal anesthesia, epidural anesthesia or combined spinal-epidural anesthesia; (3) DEX was administered via subarachnoid space route (SSR) or epidural space route (ESR); (4) only saline was used as the placebo in the control group and (5) binary data on shivering were available or the available data could be transferred into binary data. Excluded were: use of serotonin receptor agonists, central analgesics, opioids or opioid derivatives; outpatient surgery within $2 \mathrm{hrs;}$ patient with neuromuscular disease, hypothalamus or spinal injury or contraindication to DEX or S\&E anesthesia; incomplete reports; and an incorrect statistical approach.

\section{Electronic search}

Studies listed in PubMed, EMBASE, and the Cochrane Central Register of Controlled Trials were retrieved through a pilot search. The final search was run from inception to December 2017 without any restrictions. PubMed search strategies were "shivering"; "shiveringMeSH Terms"; "shiver*"; "chill"; "chill*"; and "dexmedetomidineMeSH Terms"; or "dexmedetomidine"; and "spinal"; "epidural"; "intrathecal" or "intravertebral". Bibliographies from relative articles were checked. Authors were contacted for further information if necessary.

\section{Study selection}

Titles and abstracts of all retrieved articles were screened first, and full-text screening was performed in the remaining articles for inclusion by two reviewers (Y.-Z.L. and H.-L.) independently. Discrepancies were settled through discussion.

\section{Risk of bias and quality of evidence}

Pilot risk of bias assessment and evidence assessment were first performed on two studies until consensus was reached. Risk of bias was formally assessed by two reviewers (Y.-Z.L. and Y.-J.) independently using the Cochrane Collaboration Risk of Bias tool according to 7 elements and was classified as "low," "high," or "unclear." Evidence quality was assessed using GRADE-pro software, version 3.6, according to 5 elements and was classified as "high," "moderate," "low," or "very low." Strength of evidence recommendation was assessed according to 4 elements and was classified as "strong" or "weak." Evidence quality and recommendation were performed by two reviewers (Y.-Z.L. and H.-L.). Disagreements were resolved through discussion.

\section{Data items}

Basic information from the included studies was extracted. The presence of shivering as the primary outcome was defined as any visible skeletal muscle tremors. If there was no clear definition of PAS, dichotomous data were 
extracted. Secondary outcomes were side effects, sedation and block information. Bradycardia was defined as a heart rate below $50 \mathrm{bpm}$. Hypotension was defined as a $30 \%$ reduction from the baseline of systolic blood pressure (SBP) or SBP $<90 \mathrm{mmHg}$. Any data on nausea and vomiting were directly extracted. Level of sedation greater than calmness and cooperation was considered as the presence of sedation. Time to peak level of sensory block was defined as the time to reach the maximum level. Time to peak level of motor block was defined as the time to reach a score of 3 on the Bromage scale or modified Bromage scale. Duration of sensory block was defined as 2-dermatome regression from the top sensory level. Duration of motor block was defined as the time to fall to a score of 0 on the Bromage scale or modified Bromage scale. Duration of analgesia was defined as the time of the patient request for first analgesic rescue no matter what degree of pain. Other important complications and information from each study were also extracted, if possible.

\section{Statistical analysis}

Risk ratio (RR) with 95\% confidence interval (CI) was computed for dichotomous data. Standard mean difference (SMD) with 95\% CI was computed for continuous data. Groups of more than two participants with a different dosage of IT DEX were combined into one single group. $I^{2}$ statistics were calculated to describe the level of heterogeneity, and values of $I^{2}$ greater than $50 \%$ were regarded as significantly heterogeneous. The fixed-effects model was used to pool study data when $I^{2}$ statistics were $<20 \%$; otherwise, the random-effects model was used. Sensitivity analysis was conducted by removing the study with the greatest heterogeneity and reanalyzing the remaining studies. Subgroup analysis and meta-regression were conducted if potential features existed in studies, including ethnic origin, drug administration route, surgical category and dosage. A funnel plot was drawn and interpreted by visual inspection. Data analysis was performed by two reviewers (Y.-Z.L. and X.-P. Y.) using Review Manager software, version 5.3.5 (The Nordic Cochrane Centre, Copenhagen, Denmark), and STATA, version 15.0 (Stata Corp, College Station, Texas, United States).

\section{Results}

\section{Study selection}

Of the 231 articles retrieved, 31 required a further full-text screening. Of these, eight were excluded: three for incomplete data on shivering, ${ }^{18-20}$ two for non-RCTs, ${ }^{21,22}$ one for IV administration of DEX, ${ }^{23}$ one for unavailability of the full text ${ }^{24}$ and one for conference literature. ${ }^{25}$ Authors were contacted for the missing data, but we failed to receive any replies. Finally, 22 studies meeting all eligible criteria were included in our meta-analysis (Figure 1). ${ }^{26-47}$

\section{Study characteristics}

Two studies ${ }^{45,47}$ reported post-anesthetic shivering on a 4-point shivering scale and 1 study $^{38}$ reported on a 3-point scale; the others treated post-anesthetic shivering as a secondary outcome with no clear definition. Studies were performed in India (11), ${ }^{26-36}$ China (7), ${ }^{37-43}$ Iran (2), ${ }^{44,45}$ Nepal (1) ${ }^{46}$ and Egypt (1). ${ }^{47}$ Surgical categories included Cesarean sections (7), ${ }^{37,38,40-43,45}$ lower limb (6), ${ }^{27,33-36,44}$ gynecological (4), ${ }^{33,39,46}$ urinary (3), ${ }^{28,31,33}$ lower abdominal $(3)^{30,46,47}$ and others. Injection of DEX was over SSR (14) $)^{27-33,36-41,43-47}$ and ESR (3). ${ }^{26,34,35,42}$ Via SSR, most implementations were at a dosage of $\leq 5 \mu \mathrm{g}(15)^{27-33,36-41,43-47}$ while others received $>5 \mu \mathrm{g}$ (5). ${ }^{30,33,41,43,47}$ Sample sizes ranged from 40 to 100 . Individual characteristics of each study are listed in Table 1.

\section{Study risk of bias}

Summary of the risk of bias for the 22 studies is considerably low and shown in Figure 2.

\section{Quality of evidence}

The quality of evidence was upgraded for a large effect size $\left(\mathrm{RR}_{\mathrm{PAS}}<0.5\right)$ and dose-response gradient. The final evidence level was high. The evidence recommendation was strong for the net benefits (Figure 3).

\section{Primary outcome Incidence of post-anesthetic shivering}

A total of 22 studies with 1389 patients directly reported the number of patients presenting shivering and all data were available to pool. The incidence of post-anesthetic shivering decreased from $20.10 \%$ in the control group to $10.30 \%$ in the experimental group (RR, $0.48 ; 95 \% \mathrm{CI}$, $0.39-0.59 ; \quad Z=6.86, \quad P<0.00001, \quad I^{2}=32 \%$; Figure 4). Sensitivity analysis indicated that after exclusion of the study from Shahi et al., ${ }^{34} I^{2}$ decreased from $32 \%$ to $8 \%$ (RR, $0.47 ; \quad 95 \%$ CI, $0.39-0.55 ; Z=8.67, \quad P<0.00001$ ). Subgroup analysis showed no significant difference in ethnicity, surgical category or drug administration route 


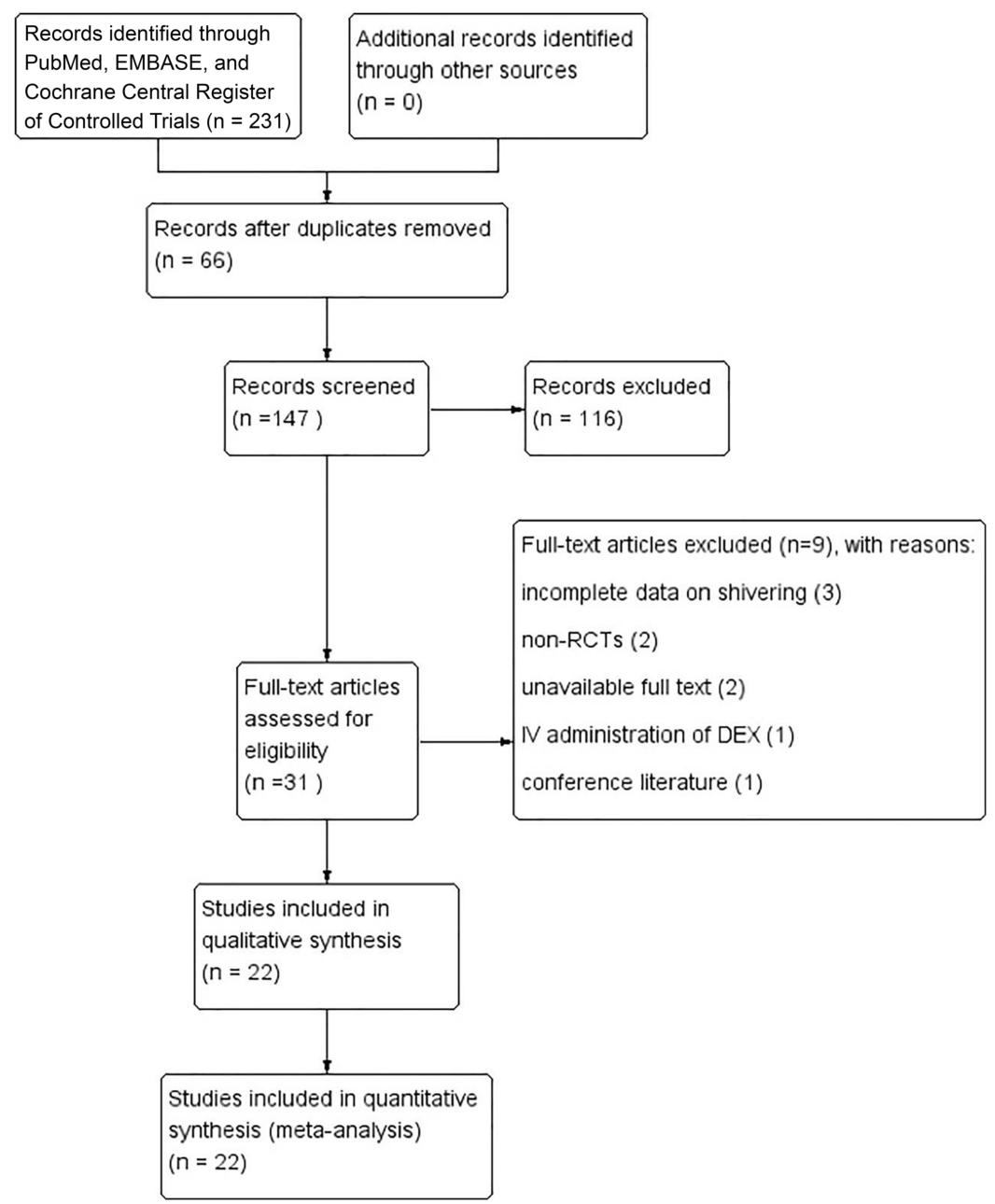

Figure I Flow diagram.

Abbreviations: RCTs, randomized controlled trials; IV, intravenous; DEX, dexmedetomidine.

$\left(I^{2}=0,0,16.6 \%\right)$. Non-Indian, SSR and cesarean subgroups (RR, 0.46, 0.44 and 0.44, respectively) showed lower risk ratios than that in the Indian, ESR and non-cesarean subgroups (RR, 0.51, 0.50 and 0.49, respectively; Figure 4). Meta-regression for PAS indicated no significant proportional change in ethnicity, drug administration route or surgical category (Coef, $0.16,-0.44$ and $-0.20 ; P=0.72$, 0.24 and 0.63 , respectively; Figure 5). In the SSR subgroup, a dosage of $>5 \mu \mathrm{g}$ showed a superior anti-shivering effect than that of $\leq 5 \mu \mathrm{g}(\mathrm{RR}, 0.23,0.60 ; 95 \% \mathrm{CI}, 0.11-$ 0.49 and $0.40-0.90$ respectively; $I^{2}, 78.9 \%$; Figure 4$)$. A funnel plot revealed visual symmetry after excluding the study of Shahi et al. ${ }^{30}$ (Figure 6). The results indicated that DEX was able to lower PAS with no significant statistical heterogeneity. Ethnicity, drug administration route or surgical category were not the sources of heterogeneity. Non-Indian and SSR groups (especially at a dose of $>5 \mu \mathrm{g}$ ) as well as cesarean subgroups showed a better anti-shivering effect. Reporting bias existed in the study of Shahi et al. ${ }^{34}$

\section{Secondary outcome Bradycardia}

A total of 18 studies reported the presence of bradycardia, and data from 12 studies $^{26,27,30,32,33,36,39,40,44-47}$ with 797 patients were available to pool. The incidence of bradycardia increased from $5.84 \%$ in the control group to $11.13 \%$ in the DEX group (RR, 2.49; 95\% CI, 1.454.28; $\left.Z=3.30, P=0.001, I^{2}, 9 \%\right)$.

\section{Hypotension}

A total of 18 studies reported the presence of hypotension, and data from 10 studies $^{26,27,30,31,33,36,39,40,44,45}$ with 646 patients were available to pool. The incidence of hypotension increased from $14.89 \%$ in the control group to $27.42 \%$ in the DEX group (RR, 2.38; 95\% CI, 0.76- 


\begin{tabular}{|c|c|c|c|c|c|c|c|c|}
\hline 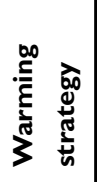 & 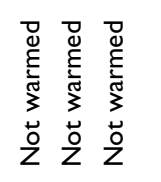 & 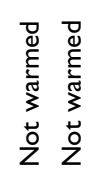 & 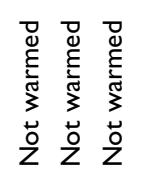 & 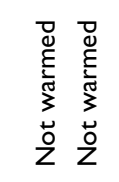 & 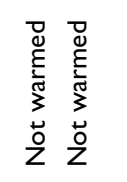 & 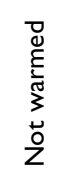 & 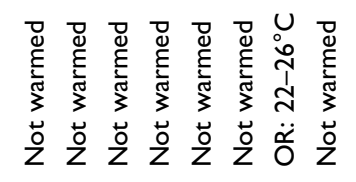 & $\begin{array}{l}u \\
\dot{U} \\
\stackrel{+}{I} \\
\ddot{\sim} \\
\ddot{0}\end{array}$ \\
\hline 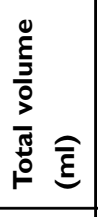 & 㒸 $\bar{m}$ & $\stackrel{n}{m} \stackrel{\circ}{m}$ & $\stackrel{n}{m} \cong \stackrel{n}{m}$ & 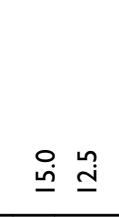 & $\stackrel{n}{m} \stackrel{i}{i}$ & $\stackrel{\circ}{m}$ & $\stackrel{\circ}{m} \stackrel{\circ}{\sim} \stackrel{\circ}{\dot{r}} \stackrel{\circ}{=} \stackrel{\circ}{m} \stackrel{\circ}{m} \stackrel{\circ}{m} \stackrel{0}{m}$ & $\stackrel{\circ}{m}$ \\
\hline 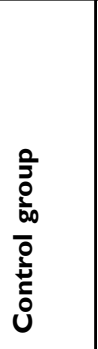 & 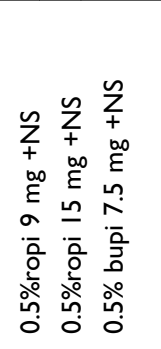 & 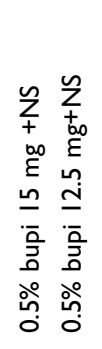 & 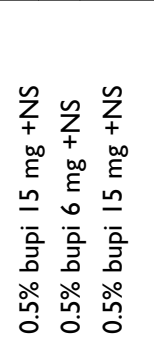 & 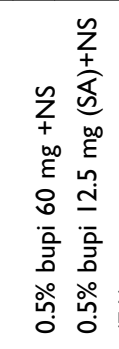 & 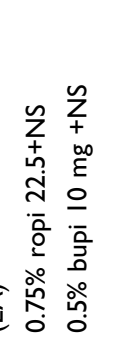 & 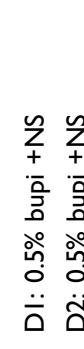 & 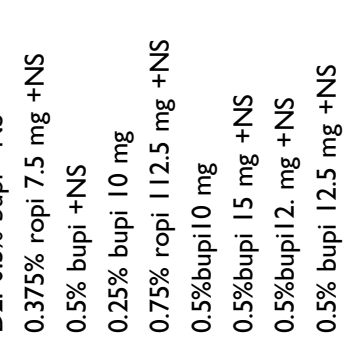 & 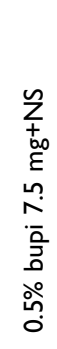 \\
\hline 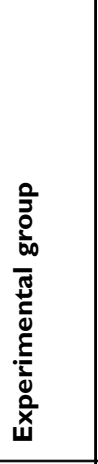 & 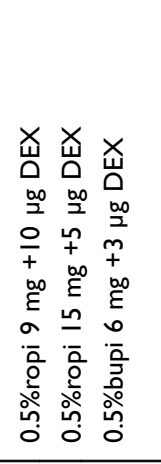 & 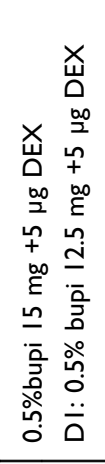 & 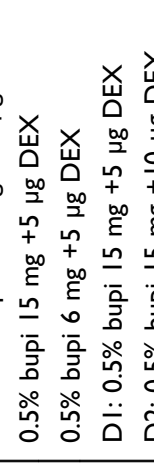 & 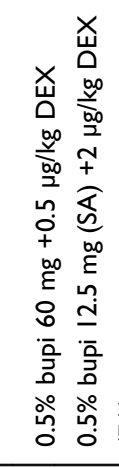 & 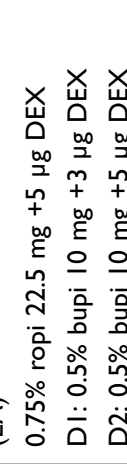 & 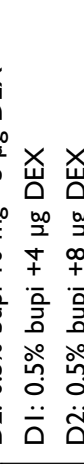 &  &  \\
\hline 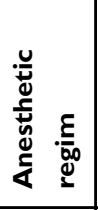 & 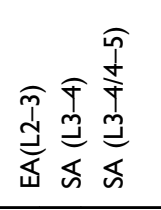 & 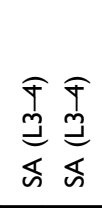 & 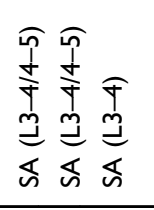 & 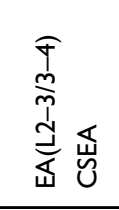 & 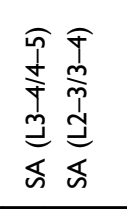 &  & 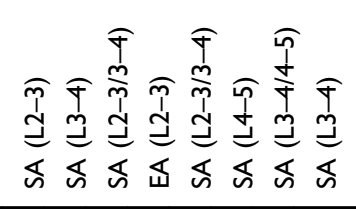 &  \\
\hline  &  &  & 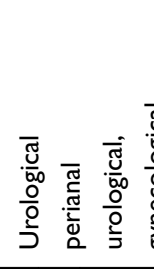 & 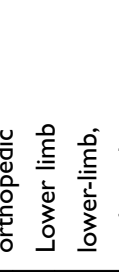 & 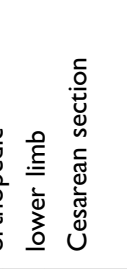 & 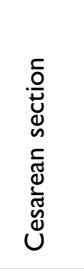 & 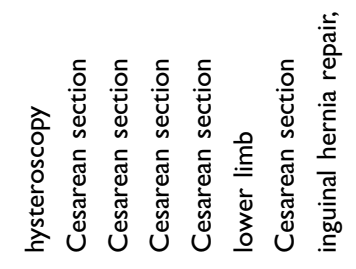 & 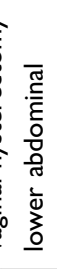 \\
\hline 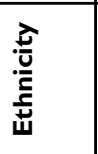 & 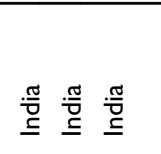 & 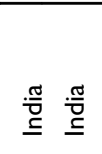 & 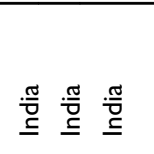 & $\underline{\underline{\underline{m}}} \underline{\underline{\underline{\pi}}}$ & 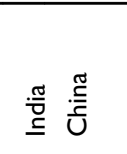 & $\underset{\frac{\pi}{E}}{\stackrel{E}{U}}$ & 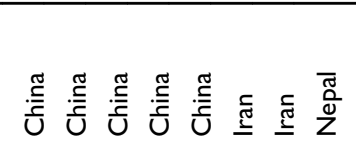 & 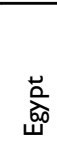 \\
\hline$\stackrel{N}{n}$ & 요용 & 음 & 앙ㅇㅇ & $₫ 8$ & $\circ:$ & 8 & 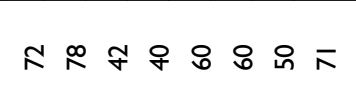 & ஃ \\
\hline خे̀ & 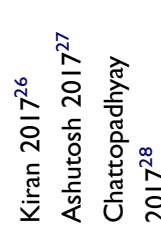 & 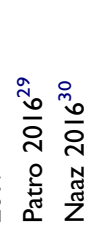 & 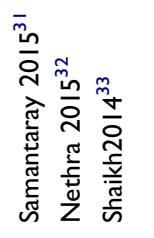 & 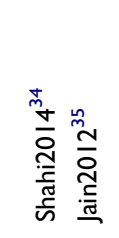 & 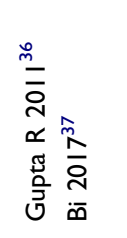 & 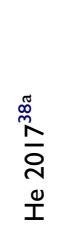 & 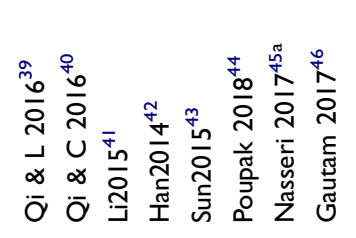 & 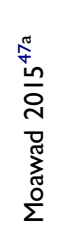 \\
\hline
\end{tabular}




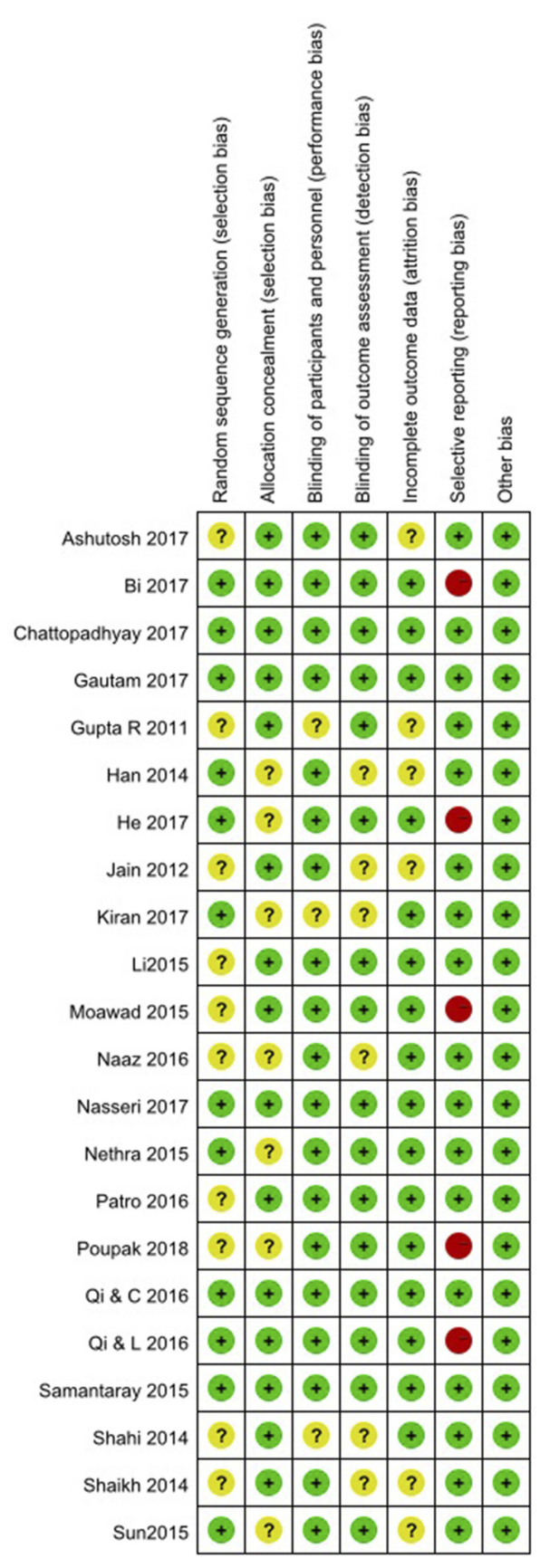

Figure 2 Risk-of-bias summary.

Abbreviations: “+”, low risk of bias; “?”, unclear risk of bias; “-”, high risk of bias.

7.64; $Z=1.49, \quad P=0.14, I^{2}=92 \%$ ). This result could not indicate that S\&E DEX increased the incidence of hypotension and had nostatisticalsignificance with large statistical heterogeneity.

\section{Nausea and vomiting}

A total of 19 studies with 1189 patients reported the presence of nausea and vomiting and all were available to pool. ${ }^{26-39,42,44-47}$ The incidence of nausea and vomiting decreased from $10.54 \%$ in the control group to $7.95 \%$ in the DEX group (RR, $0.81 ; 95 \% \mathrm{CI}, 0.58-1.15 ; Z=1.18$, $P=0.24, I^{2}=0 \%$ ). This result did not indicated that $\mathrm{S} \& \mathrm{E}$ DEX decreased the incidence of nausea and vomiting.

\section{Onset of sensory block}

Data from 11 studies $29,31,36-40,42-44,46$ with 691 patients were available to pool. The result showed S\&E DEX shortened the time to reach the peak level of sensory block (SMD, $-0.72 ; 95 \%$ CI, $-1.22-0.22 ; Z=2.84$, $\left.P=0.005, I^{2}=89 \%\right)$.

\section{Onset of motor block}

Data from 6 studies ${ }^{26,29,33,39,40,44}$ with 406 patients were available to pool. The result showed S\&E DEX shortened the time to reach Bromage3 (SMD, $-1.80 ; 95 \% \mathrm{CI},-3.15$ to $-0.45 ; Z=2.61, P=0.009, I^{2}=97 \%$ ).

\section{Duration of sensory block}

Data from 8 studies ${ }^{27-31,36,42,44}$ with 470 patients were available to pool. The result showed S\&E DEX prolonged the time of 2-dermatome regression from the top sensory level (SMD, 3.71; 95\% CI, 2.29-5.14; $Z=5.11, P<0.00001$, $\left.I^{2}=96 \%\right)$.

\section{Duration of motor block}

Data from 10 studies ${ }^{28-30,33,37,39,41,43,44,46}$ with 675 patients were available to pool. This result showed S\&E DEX prolonged the time to fall to a score of 0 on the Bromage scale or modified Bromage scale (SMD, 3.60; 95\% CI, 2.22-4.97; $Z=5.13, P<0.00001, I^{2}=98 \%$ ).

\section{Duration of analgesia}

Data from 12 studies ${ }^{26-30,32,33,36,40,42,44,46}$ with 711 patients were available to pool. This result showed S\&E DEX prolonged the time of the patient request for first analgesic rescue (SMD, 4.43; 95\% CI, 3.00-5.86; $Z=6.09$, $\left.P<0.00001, I^{2}=97 \%\right)$.

\section{Discussion}

Our systematic review and meta-analysis provide clear evidence that preventive utilization of S\&E DEX attenuates the incidence of PAS. Further evidence indicates S\&E DEX has no significant correlation with surgical type, ethnicity or drug administration route. However, via SSR, a dose of $>5 \mu \mathrm{g}$ had a better anti-shivering effect than a dose of $\leq 5 \mu \mathrm{g}$.S\&E DEX increases the incidence of bradycardia, has no effect on nausea and vomiting, shortens the onset of sensory/motor block and prolongs the duration of both sensory/motor block and analgesia; 


\begin{tabular}{|c|c|c|c|c|c|c|c|c|c|c|c|c|}
\hline \multicolumn{7}{|c|}{ Quality assessment } & \multicolumn{2}{|c|}{ No of patients } & \multicolumn{2}{|r|}{ Effect } & \multirow[b]{2}{*}{ Quality } & \multirow[b]{2}{*}{ Importance } \\
\hline $\begin{array}{c}\text { No of } \\
\text { studies }\end{array}$ & Design & Risk of bias & Inconsistency & Indirectness & Imprecision & $\begin{array}{c}\text { Other } \\
\text { considerations }\end{array}$ & IT DEX & Contriol & $\begin{array}{l}\text { Relative } \\
(95 \% \mathrm{Cl})\end{array}$ & Absolute & & \\
\hline \multicolumn{13}{|c|}{ The incidence of PAS } \\
\hline \multirow[t]{2}{*}{22} & \multirow[t]{2}{*}{$\begin{array}{l}\text { randomised } \\
\text { trials }\end{array}$} & \multirow[t]{2}{*}{$\begin{array}{l}\text { no serious } \\
\text { risk of bias }\end{array}$} & \multirow[t]{2}{*}{\begin{tabular}{|l} 
no serious \\
inconsistency
\end{tabular}} & \multirow[t]{2}{*}{$\begin{array}{l}\text { no serious } \\
\text { indirectness }\end{array}$} & \multirow[t]{2}{*}{\begin{tabular}{|l|} 
no serious \\
imprecision
\end{tabular}} & \multirow{2}{*}{$\begin{array}{l}\text { strong association }{ }^{1} \\
\text { dose response } \\
\text { gradient }^{2}\end{array}$} & \begin{tabular}{|l|}
$79 / 767$ \\
$(10.3 \%)$
\end{tabular} & $\begin{array}{l}125 / 622 \\
(20.1 \%)\end{array}$ & \multirow[t]{2}{*}{$\begin{array}{c}\text { RR } 0.48(0.39 \\
\text { to } 0.59)\end{array}$} & $\begin{array}{l}105 \text { fewer per } 1000 \text { (from } \\
82 \text { fewer to } 123 \text { fewer) }\end{array}$ & \multirow[t]{2}{*}{\begin{tabular}{|c|}
$\Theta \Theta \Theta \Theta$ \\
$\mathrm{HIGH}$
\end{tabular}} & \multirow[t]{2}{*}{ CRITICAL } \\
\hline & & & & & & & & $0 \%$ & & - & & \\
\hline
\end{tabular}

${ }^{1} \mathrm{RR}(\mathrm{PAS})<0.5$

2 Dosage $>5$ ug has better anti-shivering effect than that of $\leq 5 \mathrm{ug}$

Figure 3 Quality of evidence.

Abbreviations: IT, intrathecal; DEX, dexmedetomidine; PAS, post-anesthetic shivering.

however, its effect on hypotension remains unknown. The hierarchy of evidence quality for primary outcomes is high, and the strength of recommendation is strong.

The greatest concern regarding the off-label administration route of DEX is its neurotoxicity. However, studies have demonstrated S\&E DEX has neither a pathological impact on morphological changes in neural tissue, ${ }^{48,49}$ nor histological evidence of neurotoxicity in human beings. ${ }^{50}$ As a supplement of local anesthetics, S\&E DEX attenuates bupivacaine-induced perineural inflammation ${ }^{51}$ and lidocaine-induced cytotoxicity ${ }^{52}$ and promotes spinal-cord injury recovery by regulating apoptosis and suppressing inflammation. ${ }^{53}$ Furthermore, S\&E DEX is safe in infants and young children ${ }^{54,55}$ and shows a neuroprotective effect almost equivalent to that of methylprednisolone. ${ }^{56}$ Although the use of S\&E DEX is supported by strong scientific evidence ${ }^{57}$ and studies are emerging on its efficiency and safety, clinicians should be cautious about high cumulative dosages or concentrations, ${ }^{58,59}$ as a dosage for $5 \mu \mathrm{g} / \mathrm{kg}$ over $\mathrm{ESR}^{60}$ may induce neurotoxic effects. In our analysis, S\&E DEX is safe to use at $20 \mu \mathrm{g}$ and $2 \mu \mathrm{g} / \mathrm{kg}$ via SSR and ESR, respectively.

Our meta-analysis has primary pragmatic implications for S\&E DEX as it reduces PAS prophylactically. However, one included study in our review by Shahi et al. $^{34}$ shows that S\&E DEX increased the incidence of PAS (D, 30\%; C, 12.5\%), which is contrary to the results of the remaining 21 studies. Their study contributes $24 \%$ of total heterogeneity and may therefore have reporting bias according to our funnel plot. No study has yet reported that DEX increased PAS. They ascribed this to DEX-induced hypothermia, but Moawad et al. ${ }^{47}$ demonstrated that perioperative body temperature is slightly higher for S\&E DEX compared to placebo. In the end, we did not exclude their data because no distinct method or clinical heterogeneity was found. Our subgroup analysis and meta-regression could not statistically infer whether ethnicity, drug administration route or surgical category was the source of heterogeneity. We suggested that S\&E DEX used in non-Indian patients undergoing cesarean section via ESR might have a better anti-shivering effect, but this needs further exploration because of our small simple size, especially in the ESR group. We did not conduct a meta-regression on dosage because different administration routes existed in the same dosage. In the SSR subgroup, we tried to find a dose-dependent effect by dividing the studies into $>5 \mu \mathrm{g}$ and $\leq 5 \mu \mathrm{g}$ dosages. We concluded that S\&E DEX in a dosage $>5 \mu \mathrm{g}$ had a better anti-shivering effect than a dosage of $\leq 5 \mu \mathrm{g}$.

We note that meta-analysis from Zhang et al. ${ }^{61}$ suggested that S\&E DEX reduced the incidence of PAS and was moreeffective with a dose of 5 ug via SSR, especially in cesarean section; this finding partly agreed with our study. However, they included 15studies less than than our meta-analysis as well as enrolled non-randomized controlled trials (non-RCTs), including some studies that had confounding factors in experimental groups, and did not evaluate evidence quality or run a meta-regression. Another meta-analysis from Liu et al. ${ }^{62}$ included 5 studies and assured the efficacy of S\&E DEX for PAS (which agreed with ours). However, they opposed S\&E DEX for the high price and hemodynamic fluctuations. Regardless, DEX has been included in the medical insurance systems of many countries, and its hemodynamic fluctuations have been shown to be tolerable.

Secondary outcomes emerged from our meta-analysis. First, our hemodynamic information was in agreement with that of other meta-analysies. ${ }^{61,63,64}$ We confirmed that S\&E DEX increases the incidence of bradycardia, but could not suggest that S\&E DEX increases the 


\begin{tabular}{|c|c|c|c|c|c|c|c|c|}
\hline Study or Subgreup & \multicolumn{2}{|c|}{ Experimental } & \multicolumn{2}{|c|}{ Control } & Weight & $\begin{array}{l}\text { Risk ratio } \\
M-H, \text { random, } 95 \% \mathrm{Cl}\end{array}$ & \multicolumn{2}{|c|}{$\begin{array}{c}\text { Risk ratio } \\
\mathrm{M}-\mathrm{H}, \quad \text { random, } 95 \% \mathrm{Cl}\end{array}$} \\
\hline \multicolumn{9}{|l|}{ 1.1.1 India } \\
\hline Ashutosh 2017 & 1 & 25 & 2 & 25 & $0.7 \%$ & $0.50[0.05,5.17]$ & & \\
\hline Chattopadhyay 2017 & 2 & 30 & 2 & 30 & $1.0 \%$ & $1.00[0.15,6.64]$ & & \\
\hline Gupta R 2011 & 0 & 30 & 1 & 30 & $0.4 \%$ & $0.33[0.01,7.87]$ & & \\
\hline Jain 2012 & 1 & 30 & 8 & 30 & $0.9 \%$ & $0.13[0.02,0.94]$ & & \\
\hline Kiran 2017 & 2 & 25 & 3 & 21 & $1.2 \%$ & $0.56[0.10,3.04]$ & & \\
\hline Naaz 2016 & 5 & 80 & 7 & 20 & $2.5 \%$ & $0.18[0.06,0.50]$ & & \\
\hline Nethra 2015 & 0 & 20 & 1 & 20 & $0.4 \%$ & $0.33[0.01,7.72]$ & & \\
\hline Patro 2016 & 1 & 30 & 2 & 30 & $0.7 \%$ & $0.50[0.05,5.22]$ & & \\
\hline Samantaray 2015 & 1 & 20 & 1 & 20 & $0.5 \%$ & $1.00[0.07,14.90]$ & & \\
\hline Shahi 2014 & 12 & 40 & 5 & 40 & $2.7 \%$ & $2.40[0.93,6.19]$ & & \\
\hline Shaikh 2014 & 0 & 60 & 1 & 30 & $0.4 \%$ & $0.17[0.01,4.04]$ & & \\
\hline Subtotal $(95 \% \mathrm{Cl})$ & & 390 & & 296 & $11.5 \%$ & $0.51[0.24,1.09]$ & & \\
\hline Total events & 25 & & 33 & & & & & \\
\hline \multicolumn{9}{|c|}{ Heterogeneity: $\operatorname{Tau}^{2}=0.61 ; C h i^{2}=17.14, \mathrm{df}=10(P=0.07) ; I^{2}=42 \%$} \\
\hline \multicolumn{9}{|c|}{ Test for overall effect: $Z=1.75(P=0.08)$} \\
\hline \multicolumn{9}{|l|}{ 1.1.2 non-india } \\
\hline Bi 2017 & 17 & 40 & 11 & 20 & $4.4 \%$ & $0.77[0.45,1.32]$ & & \\
\hline Gautam 2017 & 4 & 36 & 11 & 35 & $2.4 \%$ & $0.35[0.12,1.01]$ & & \\
\hline Han 2014 & 1 & 20 & 8 & 20 & $0.9 \%$ & $0.13[0.02,0.91]$ & & \\
\hline He 2017 & 12 & 60 & 11 & 30 & $3.7 \%$ & $0.55[0.27,1.09]$ & & \\
\hline Li2015 & 0 & 21 & 3 & 21 & $0.5 \%$ & $0.14[0.01,2.61]$ & & \\
\hline Moawad 2015 & 2 & 40 & 13 & 40 & $1.6 \%$ & $0.15[0.04,0.64]$ & & \\
\hline Nasseri 2017 & 1 & 25 & 4 & 25 & $0.8 \%$ & $0.25[0.03,2.08]$ & & \\
\hline Poupak 2018 & 1 & 30 & 2 & 30 & $0.7 \%$ & $0.50[0.05,5.22]$ & & \\
\hline Qi \& C 2016 & 3 & 39 & 14 & 39 & $2.1 \%$ & $0.21[0.07,0.69]$ & & \\
\hline Qi \& L 2016 & 12 & 36 & 14 & 36 & $4.0 \%$ & $0.86[0.46,1.59]$ & & \\
\hline Sun2015 & 1 & 30 & 1 & 30 & $0.5 \%$ & $1.00[0.07,15.26]$ & & \\
\hline Subtotal $(95 \% \mathrm{Cl})$ & & 377 & & 326 & $21.8 \%$ & $0.46[0.30,0.71]$ & & \\
\hline Total events & 54 & & 92 & & & & & \\
\hline \multicolumn{9}{|c|}{ Heterogeneity: $\operatorname{Tau}^{2}=0.15 ; C h i^{2}=15.26, d f=10(P=0.12) ; I^{2}=34 \%$} \\
\hline \multicolumn{9}{|c|}{ Test for overall effect: $Z=3.55(P=0.0004)$} \\
\hline \multicolumn{9}{|l|}{ 1.1.3 ESR } \\
\hline Han 2014 & 1 & 20 & 8 & 20 & $0.9 \%$ & $0.13[0.02,0.91]$ & & \\
\hline Jain 2012 & 1 & 30 & 8 & 30 & $0.9 \%$ & $0.13[0.02,0.94]$ & & \\
\hline Kiran 2017 & 2 & 25 & 3 & 21 & $1.2 \%$ & $0.56[0.10,3.04]$ & & \\
\hline Shahi 2014 & 12 & 40 & 5 & 40 & $2.7 \%$ & $2.40[0.93,6.19]$ & & \\
\hline Subtotal $(95 \% \mathrm{CI})$ & & 115 & & 111 & $5.8 \%$ & $0.44[0.09,2.28]$ & & \\
\hline Total events & 16 & & 24 & & & & & \\
\hline Heterogeneity: $\operatorname{Tau}^{2}=$ & 06; Chi ${ }^{2}$ & 12.55 & $d f=3(P=$ & $=0.006$ & $; I^{2}=76 \%$ & & & \\
\hline Test for overall effect: & $=0.97(P$ & $=0.33)$ & & & & & & \\
\hline 1.1.4 SSR & & & & & & & & \\
\hline Ashutosh 2017 & 1 & 25 & 2 & 25 & $0.7 \%$ & $0.50[0.05,5.17]$ & & \\
\hline Bi 2017 & 17 & 40 & 11 & 20 & $4.4 \%$ & $0.77[0.45,1.32]$ & & - \\
\hline Chattopadhyay 2017 & 2 & 30 & 2 & 30 & $1.0 \%$ & $1.00[0.15,6.64]$ & & \\
\hline Gautam 2017 & 4 & 36 & 11 & 35 & $2.4 \%$ & $0.35[0.12,1.01]$ & & \\
\hline Gupta R 2011 & 0 & 30 & 1 & 30 & $0.4 \%$ & $0.33[0.01,7.87]$ & & \\
\hline $\mathrm{He} 2017$ & 12 & 60 & 11 & 30 & $3.7 \%$ & $0.55[0.27,1.09]$ & & \\
\hline Li2015 & 0 & 21 & 3 & 21 & $0.5 \%$ & $0.14[0.01,2.61]$ & & \\
\hline Moawad 2015 & 2 & 40 & 13 & 40 & $1.6 \%$ & $0.15[0.04,0.64]$ & & \\
\hline Naaz 2016 & 5 & 80 & 7 & 20 & $2.5 \%$ & $0.18[0.06,0.50]$ & & \\
\hline Nasseri 2017 & 1 & 25 & 4 & 25 & $0.8 \%$ & $0.25[0.03,2.08]$ & & \\
\hline Nethra 2015 & 0 & 20 & 1 & 20 & $0.4 \%$ & $0.33[0.01,7.72]$ & & \\
\hline Patro 2016 & 1 & 30 & 2 & 30 & $0.7 \%$ & $0.50[0.05,5.22]$ & & \\
\hline Poupak 2018 & 1 & 30 & 2 & 30 & $0.7 \%$ & $0.50[0.05,5.22]$ & & \\
\hline Qi \& C 2016 & 3 & 39 & 14 & 39 & $2.1 \%$ & $0.21[0.07,0.69]$ & & \\
\hline Qi \& L 2016 & 12 & 36 & 14 & 36 & $4.0 \%$ & $0.86[0.46,1.59]$ & & \\
\hline Samantaray 2015 & 1 & 20 & 1 & 20 & $0.5 \%$ & $1.00[0.07,14.90]$ & & \\
\hline Shaikh 2014 & 0 & 60 & 1 & 30 & $0.4 \%$ & $0.17[0.01,4.04]$ & & \\
\hline Sun2015 & 1 & 30 & 1 & 30 & $0.5 \%$ & $1.00[0.07,15.26]$ & & \\
\hline Subtotal $(95 \% \mathrm{Cl})$ & & 652 & & 511 & $27.5 \%$ & $0.50[0.37,0.68]$ & & \\
\hline Total events & 63 & & 101 & & & & & \\
\hline Heterogeneity: $\operatorname{Tau}^{2}=$ & $02 ; \mathrm{Chi}^{2}$ & 18.01, & $d f=17(P$ & 0.39 & $; I^{2}=6 \%$ & & & \\
\hline Test for overall effect: & $=4.51(\mathrm{P}$ & $<0.000$ & & & & & & \\
\hline
\end{tabular}

Figure 4 Continued. 


\begin{tabular}{|c|c|c|c|c|c|}
\hline \multicolumn{6}{|l|}{ 1.1.5 cesarean } \\
\hline Bi 2017 & 17 & 40 & 11 & 20 & $4.4 \%$ \\
\hline Han 2014 & 1 & 20 & 8 & 20 & $0.9 \%$ \\
\hline He 2017 & 12 & 60 & 11 & 30 & $3.7 \%$ \\
\hline Li2015 & 0 & 21 & 3 & 21 & $0.5 \%$ \\
\hline Nasseri 2017 & 1 & 25 & 4 & 25 & $0.8 \%$ \\
\hline Qi \& C 2016 & 3 & 39 & 14 & 39 & $2.1 \%$ \\
\hline Sun2015 & 1 & 30 & 1 & 30 & $0.5 \%$ \\
\hline Subtotal $(95 \% \mathrm{Cl})$ & & 235 & & 185 & $13.0 \%$ \\
\hline Total events & 35 & & 52 & & \\
\hline \multicolumn{6}{|c|}{$\begin{array}{l}\text { Heterogeneity: } \operatorname{Tau}^{2}=0.17 ; \mathrm{Ch}^{2}=9.04, d f=6(P=0.17) ; l^{2}=34 \% \\
\text { Test for overall effect: } Z=2.80(P=0.005)\end{array}$} \\
\hline \multicolumn{6}{|l|}{ 1.1.6 non-cesarean } \\
\hline Ashutosh 2017 & 1 & 25 & 2 & 25 & $0.7 \%$ \\
\hline Chattopadhyay 2017 & 2 & 30 & 2 & 30 & $1.0 \%$ \\
\hline Gautam 2017 & 4 & 36 & 11 & 35 & $2.4 \%$ \\
\hline Gupta R 2011 & 0 & 30 & 1 & 30 & $0.4 \%$ \\
\hline Jain 2012 & 1 & 30 & 8 & 30 & $0.9 \%$ \\
\hline Kiran 2017 & 2 & 25 & 3 & 21 & $1.2 \%$ \\
\hline Moawad 2015 & 2 & 40 & 13 & 40 & $1.6 \%$ \\
\hline Naaz 2016 & 5 & 80 & 7 & 20 & $2.5 \%$ \\
\hline Nethra 2015 & 0 & 20 & 1 & 20 & $0.4 \%$ \\
\hline Patro 2016 & 1 & 30 & 2 & 30 & $0.7 \%$ \\
\hline Poupak 2018 & 1 & 30 & 2 & 30 & $0.7 \%$ \\
\hline Qi \& L 2016 & 12 & 36 & 14 & 36 & $4.0 \%$ \\
\hline Samantaray 2015 & 1 & 20 & 1 & 20 & $0.5 \%$ \\
\hline Shahi 2014 & 12 & 40 & 5 & 40 & $2.7 \%$ \\
\hline Shaikh 2014 & 0 & 60 & 1 & 30 & $0.4 \%$ \\
\hline Subtotal $(95 \% \mathrm{Cl})$ & & 532 & & 437 & $20.3 \%$ \\
\hline Total events & 44 & & 73 & & \\
\hline \multirow{2}{*}{\multicolumn{6}{|c|}{$\begin{array}{l}\text { Heterogeneity: } \operatorname{Tau}^{2}=0.36 ; \mathrm{Ch}^{2}=23.11, d f=14(P=0.06) ; I^{2}=39 \% \\
\text { Test for overall effect: } Z=2.65(P=0.008)\end{array}$}} \\
\hline & & & & & \\
\hline Total $(95 \% \mathrm{Cl})$ & & 2301 & & 1866 & $100.0 \%$ \\
\hline Total events & 237 & & 375 & & \\
\hline \multirow{2}{*}{\multicolumn{6}{|c|}{$\begin{array}{l}\text { Heterogeneity: } \operatorname{Tau}^{2}=0.18 ; \mathrm{Ch}^{2}=95.18, d f=65(P=0.009) ; I^{2}=32 \% \\
\text { Test for overall effect: } Z=6.86(P<0.00001)\end{array}$}} \\
\hline & & & & & \\
\hline Test for subaroun diff & es: $\mathrm{Cl}$ & $=0.22$ & 5 & 1. & $z=0 \%$ \\
\hline
\end{tabular}

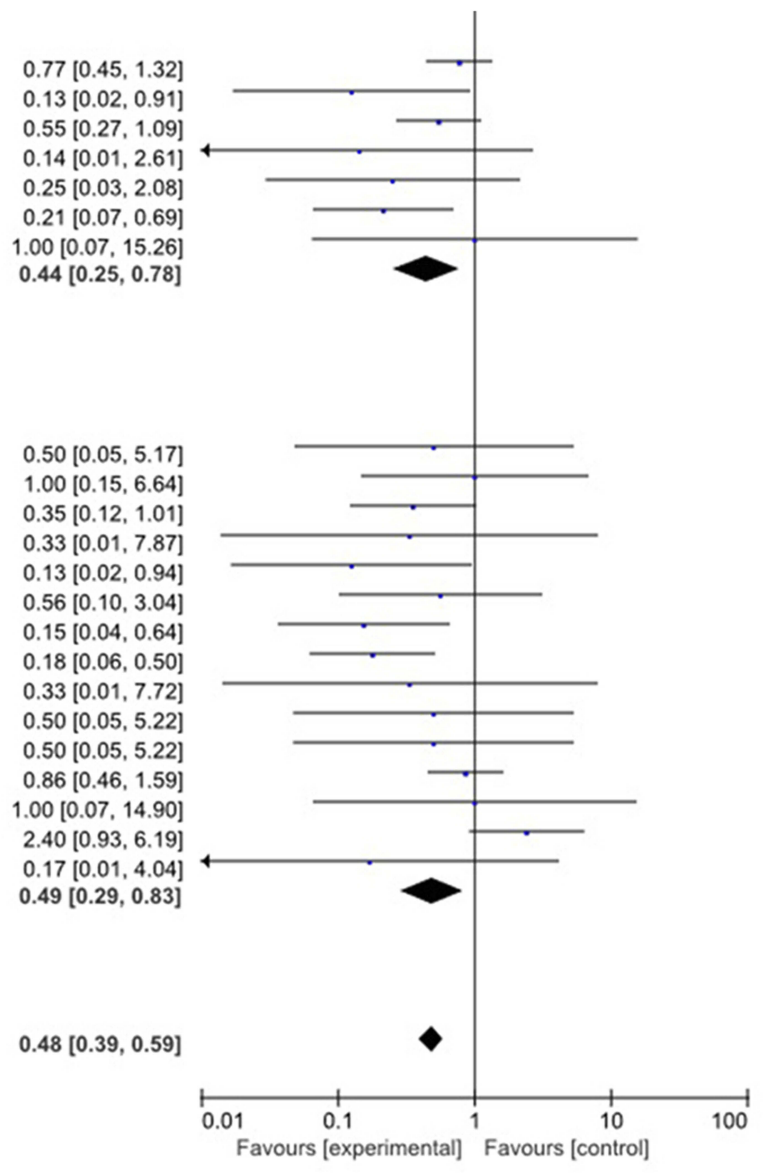

Figure 4 Forest plot for PAS.

Abbreviations: ESR, epidural-space route; SSR, subarachnoid-space route.

- metareg ES ethnic route surgery, wsse(_selogEs) bsest (reml)

Iteration 1: $\operatorname{tau} \wedge 2=0$

Iteration 2: $\operatorname{tau}{ }^{\wedge}=.0548216$

Iteration 3: $\operatorname{tau} \wedge 2=.07810897$

Iteration 4: $\operatorname{tau} \wedge 2=.07919806$

Meta-analysis regression

No of Studies $=20$

tau^2 method reml

tau^2 estimate $=.0792$

Sucessive values of tau^2 differ by less than 10^-4 :convergence achieved

\begin{tabular}{r|rrrrrr}
\hline & Coef. & Std. Err. & $z$ & P > |z| & [95\% Conf. Interval] \\
\hline ethnic & .2457101 & .4663164 & 0.53 & 0.598 & -.6682533 & 1.159673 \\
route & -.5111932 & .4019835 & -1.27 & 0.203 & -1.299066 & .27668 \\
surgery & -.2045483 & .4173179 & -0.49 & 0.624 & -1.022476 & .6133797 \\
cons & 1.088097 & .5041888 & 2.16 & 0.031 & .0999047 & 2.076289 \\
\hline
\end{tabular}

Figure 5 Meta-regression. 


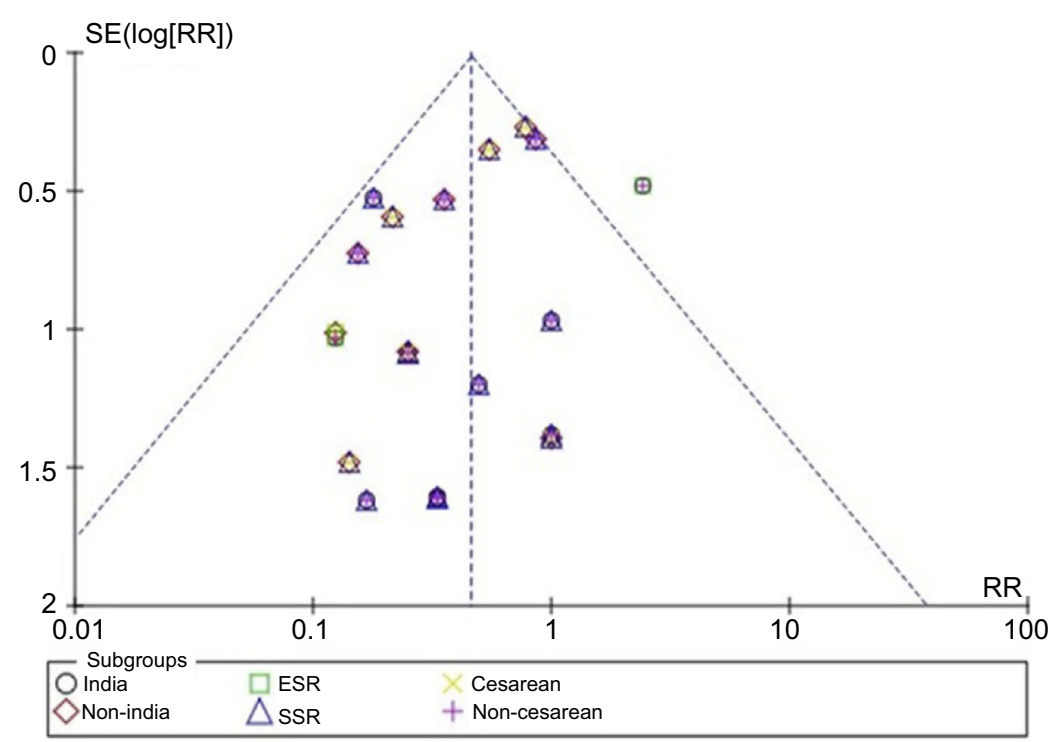

Figure 6 Funnel plot for PAS. Study from Shahi et al falls outside of the funnel plot.

incidence of hypotension because $95 \% \mathrm{CI}$ of RR stretched across 1 and heterogeneity was tremendous $\left(I^{2}=92 \%\right)$. Second, we deduced that S\&E DEX had no impact on the incidence of nausea and vomiting, which was consistent with other studies. ${ }^{63}$ Third, we concluded S\&E DEX significantly shortened the onset time of peak block level and prolonged both sensory/motor block and analgesia. Although significant heterogeneity $\left(I^{2}>95 \%\right)$ exists in these pooled data, the overall effect size was large and meaningful, which was similar to thatfound in previous studies. $^{65,66}$ However, these resultsshould be considered from a practical outlook as to whether this prolongation comes at the cost of longer hospital stays and increased patient burdens. We suggest that S\&E DEX is not applicable for outpatients undergoing short surgeries (<60 min). Finally, each included study showed that S\&E DEX deepened sedation compared with the placebo, which agreed with other studies. ${ }^{67,68}$

Compared with previous studies, our study has unique strengths. First, we introduce strict eligibility by retrieving only RCTs and excluding studies using serotonin receptor agonists, central analgesics, opioids or opioid derivatives in case of their interferential and controversial anti-shivering effects. It is clear that DEX has an anti-shivering effect since no evidence has been revealed otherwise. Moreover, a study by Hocker et al. ${ }^{69}$ suggests that meperidine exerts an anti-shivering effect by decreasing the shivering threshold only through an $\alpha_{2 \mathrm{~A}}$-receptor but not a $\mu$-receptor. A recent meta-analysis by Zhou et al. ${ }^{70}$ shows that serotonin receptor antagonist ondansetron has no anti-shivering effect. To obtain the net effect of S\&E DEX, we intentionally omitted drugs (fentanyl, butorphanol) from our original eligibility criteria with the controversial auxiliary component to combine with local anesthetics that act as plausible confounding factors. Second, we dismissed doubts over roles of ethnicity, surgical category, and route of drug administration by conducting meta-regression and found no source of heterogeneity. Finally, we graded the quality of evidence and provided recommendations for clinical application.

Our meta-analysis has some limitations. First, all reviewed studies have small sample sizes (20-50 patients/group) and a small number of PAS, which increases the probability of type I error and reporting bias. Second, study from Shahi et al. ${ }^{34}$ has the inverse result and considerable reporting bias (asymmetry of funnel plot), but it does not change the overall result, and the level of heterogeneity is acceptable. Third, all included studies report shivering through visual inspection but not instrument detection, and three articles used the shivering scale, which may underestimate the incident of PAS when patients are in a pre-shivering condition such as peripheral vasoconstriction. Fourth, the ethnic concentricity in India and China may limit the generalization of our findings, and therefore studies involving other ethnicities are needed. Fifth, on account of inconsistent sedation scales and different measuring times, most details regarding the number of events at each sedation level in the same endpoint were unavailable for extraction. lastly, the full text from Gangadhara et al. ${ }^{24}$ was not available from the authors, 
thus, we believe that future meta-analyses can cover this shortage.

Several issues need to be addressed. First, owing to different pharmacodynamics and pharmacokinetics of children to adults, we did not include pediatric studies. Second, few studies report on temperature, which restricted us from distinguishing whether temperature has an effect on PAS.

\section{Conclusion}

In this study, we demonstrate that as an adjuvant drug, prophylactic S\&E DEX attenuates PAS. Moreover, a dose of $>5 \mu \mathrm{g}$ over SSR has a better anti-shivering effect than a dose of $\leq 5 \mu \mathrm{g}$. However, this is not applicable to megadoses, high concentrations or outpatients. This conclusion should be interpreted cautiously when patients have an underlying disease such as bradycardia.

\section{Abbreviations}

PAS, Post-anesthetic shivering; BSAS, Bedside Shivering Assessment Scale; DEX, Dexmedetomidine; IV, Intravenous; S\&E, Subarachnoid and epidural; nonRCTs, Randomized controlled trials; SSR, Subarachnoidspace route; ESR, Epidural-space route; SBP, Systolic blood pressure; RR, Risk ratio; CI, Confidence interval; SMD, Standard mean difference.

\section{Acknowledgments}

National Natural Science Foundation of China (81471448) and the Natural Science Foundation of Zhejiang Province (Y14H090071). The sponsors had no involvement from study design to submission of the paper for publication.

\section{Author contributions}

All authors contributed to data analysis, drafting or revising the article, gave final approval of the version to be published, and agree to be accountable for all aspects of the work.

\section{Disclosure}

The authors report no conflicts of interest in this work.

\section{References}

1. Shu YL, Ping L, Xue ML. Efficacy of the prophylactic administration of tramadol against postoperative shivering: a meta-analysis of randomized controlled trials. Minerva Anestesiol. 2017;83(1):79-87. doi:10.23736/S0375-9393.16.11351-3
2. Reynolds L, Beckmann J, Kurz A. Perioperative complications of hypothermia. Best Pract Res Clin Anaesthesiol. 2008;22:645-657. doi:10.1016/j.bpa.2008.07.005

3. Eberhart L, Döderlein F, Eisenhardt GRN, et al. Independent risk factors for postoperative shivering. Anesth Analg. 2005;101:1849. doi:10.1213/01.ANE.0000184128.41795.FE

4. Tsukamoto M, Hitosugi T, Esaki K, Yokoyama T. Risk factors for postoperative shivering after oral and maxillofacial surgery. Brit $J$ Oral Max Surg. 2016;74:2359-2362. doi:10.1016/j.joms.20 16.06.180

5. Leslie K, Sessler DI. Reduction in the shivering threshold is proportional to spinal block height. Anesthesiology. 1996;84:1327-1331. doi:10.1097/00000542-199606000-00008

6. Olson D, Grissom J, Williamson R, Bennett S, Bellows S, James M. Interrater reliability of the bedside shivering assessment scale. Am J Critl Care. 2013;22:70-74. doi:10.4037/ajcc2013907

7. Alderson P, Campbell G, Smith AF, Warttig S, Nicholson A, Lewis SR. Thermal insulation for preventing inadvertent perioperative hypothermia. J Perianesth Nurs. 2015;30:427-429. doi:10.1016/j. jopan.2015.08.002

8. Campbell G, Alderson P, Smith AF, Warttig S. Warming of intravenous and irrigation fluids for preventing inadvertent perioperative hypothermia. Cochrane Db Syst Rev. 2015;4:CD009891. doi:10.1002/14651858.CD009891.pub2.

9. Clifton WC, Jonathan E, Francis XG, et al. Dexmedetomidine reduces shivering during mild hypothermia in waking subjects. PLoS One. 2015;10:0129709.

10. Talke P, Tayefeh F, Sessler DI, Jeffrey R, Noursalehi M, Richardson C. Dexmedetomidine does not alter the sweating threshold, but comparably and linearly decreases the vasoconstriction and shivering thresholds. Anesthesiology. 1997;87:835. doi:10.1097/00000542199710000-00017

11. Baiula M, Bedini A, Spampinato SM. Role of nociceptin/orphanin FQ in thermoregulation. Neuropeptides. 2015;50:51-56. doi:10.1016/ j.npep.2015.03.005

12. Hoffman J, Hamner C. Effectiveness of dexmedetomidine use in general anesthesia to prevent postoperative shivering: a systematic review protocol. Jbi Db Syst Rev Implem Reports. 2015;13:37-48. doi:10.11124/jbisrir-2015-1902

13. Monteleone $\mathrm{M}$, Teng $\mathrm{H}$. Intravenous dexmedetomidine as an 'adjuvant' to the infant spinal anesthetic. PaediatrAnaesth. 2016;26:12141215.

14. Tomar G, Tiwari A, Ganguly S. Prospective comparative study of analgesic efficiency of paravertebral block with ropivacaine $(0.2 \%)$ and dexmedetomidine + ropivacaine $(0.2 \%)$ in renal surgeries. Anesth Analg. 2012;114:360.

15. Kida K, Ohtani N, Shoji K, Yasui Y, Masaki E. Postoperative pain status after intraoperative systemic dexmedetomidine and epidural neostigmine in patients undergoing lower abdominal surgery. Eur $J$ Anaesthesiol. 2008;25:869-875. doi:10.1017/S0265021508004493

16. Kang P, Park SK, Yoo S, et al. Comparative effectiveness of pharmacologic interventions to prevent shivering after surgery: a network meta-analysis. Minerva Anestesiol. 2019;85(1):60-70. doi:10.23736/ S0375-9393.18.12813-6

17. Liu J, Wang Y, Ma W. Shivering prevention and treatment during cesarean delivery under neuraxial anesthesia: a systematic review. Minerva Anestesiol. 2018. doi:10.23736/S0375-9393.18.12478-3

18. Shreepad KS, Amol AS, Kalpana H. Comparative analysis of epidural bupivacaine versus bupivacaine with dexmedetomidine for vaginal hysterectomy. Anesthesia Essays Research. 2015;9:310-313. doi:10.4103/0259-1162.158007

19. Jamliya RH, Deshmukh V, Rajesh C, Shah MH. Effect of adding dexmedetomidine in intrathecal bupivacaine versus intrathecal bupivacaine alone on spinal block characteristics in orthopaedic lower limb procedures. Research J Pharm Biolog Chem Sci. 2013;4:1340-1346. 
20. Soni P. Comparative study for better adjuvant with ropivacaine in epidural anesthesia. Anesthesia Essays Research. 2016;10:218. doi:10.4103/0259-1162.174470

21. Salgado PF, Sabbag AT, Silva PC, et al. Synergistic effect between dexmedetomidine and $0.75 \%$ ropivacaine in epidural anesthesia. Revista Da AssociaçãoMédicaBrasileira. 2008;54:110.

22. Zeng X, Xu Y, Cui X, Guo Y, Li W. Low-dose epidural dexmedetomidine improves thoracic epidural anaesthesia for nephrectomy. Anaesth Inten Care. 2014;42:185-190.

23. Burhanettin U, Muhammet G, Irem D, Bunyamin M, Huseyin S, Adnan Y. Dexmedetomidine for the prevention of shivering during spinal anesthesia. Clinics. 2011;66:1187-1191. doi:10.1590/s180759322011000700011

24. Gowda KG, Hanji SA. Effect of intrathecal dexmedetomidine on the characteristics of bupivacaine spinal block in orthopaedic surgeries. Indian J Pub Health Research Develop. 2015;6:63-66. doi:10.5958/ 0976-5506.2015.00140.0

25. Gupta N, Gupta A. A prospective randomised double blind study to evaluate the effect of intrathecal low dose dexmedetomidine versus clonidine on spinal block characteristics in surgeries below umbilicus. Anesth Analg. 2013;116:276.

26. Kiran S, Kavita J, Urvashi T, Soumita K. Evaluation of dexmedetomidine and fentanyl as additives to ropivacaine for epidural anesthesia and postoperative analgesia. J Anaesthesiol Clinic Pharm. 2018;34(1):41.

27. Ashutosh KS, Abhyuday K, Ashok K, Braj KP, Pradeep KT, Ranjeet $\mathrm{K}$. A comparison of intrathecal dexmedetomidine and neostigmine as adjuvant to ropivacaine for lower limb surgeries: a double-blind randomized controlled study. Anesth Essays Research. 2017;11 (4):987.

28. Chattopadhyay I, Banerjee SS, Jha AK, Basu S. Effects of intrathecal dexmedetomidine as an additive to low-dose bupivacaine in patients undergoing transurethral resection of prostate. Indian J Anaesth. 2017;61:1002-1008. doi:10.4103/ija.IJA_324_16

29. Patro SS, Deshmukh H, Ramani YR, Das G. Evaluation of dexmedetomidine as an adjuvant to intrathecal bupivacaine in infraumbilical surgeries. J Clinic Diag Research Jcdr. 2016;10:13.

30. Naaz S, Bandey J, Ozair E, Asghar A. Optimal dose of intrathecal dexmedetomidine in lower abdominal surgeries in average Indian adult. J Clinic Diag Research Jcdr. 2016;10:09.

31. Samantaray A, Hemanth N, Gunnampati K, Pasupuleti H, Mukkara $\mathrm{M}$, Rao MH. Comparison of the effects of adding dexmedetomidine versus midazolam to intrathecal bupivacaine on postoperative analgesia. Pain Physician. 2015;18:71.

32. Nethra SS, Sathesha M, Dixit A, Dongare PA, Harsoor SS, Devikarani D. Intrathecal dexmedetomidine as adjuvant for spinal anaesthesia for perianal ambulatory surgeries: a randomised doubleblind controlled study. Indian $J$ Anaesth. 2015;59:177-181. doi:10.4103/0019-5049.153040

33. Shaikh SI, Dattatri R. Dexmedetomidine as an adjuvant to hyperbaric spinal bupivacaine for infra-umbilical procedures: a dose related study. Anaesth Pain Intens Care. 2014;18:180-185.

34. Shahi V, Verma AK, Agarwal A, Singh CS. A comparative study of magnesium sulfate vs dexmedetomidine as an adjunct to epidural bupivacaine. J Anaesthesiol Clinic Pharm. 2014;30:538-542. doi:10.4103/0970-9185.142852

35. Jain D, Khan RM, Kumar D, Kumar N. Perioperative effect of epidural dexmedetomidine with intrathecal bupivacaine on haemodynamic parameters and quality of analgesia. South Afric J Anaesth Analg. 2012;18:105-109.

36. Gupta R, Bogra J, Verma R, Kohli M, Kushwaha JK, Kumar S. Dexmedetomidine as an intrathecal adjuvant for postoperative analgesia. Indian J Anaesth. 2011;55:347-351. doi:10.4103/00195049.84841
37. Bi YH, Cui XG, Zhang RQ, Song CY, Zhang YZ. Low dose of dexmedetomidine as an adjuvant to bupivacaine in cesarean surgery provides better intraoperative somato-visceral sensory block characteristcsand postoperative analgesia. Oncotarget. 2017;8 (83):63587-63595. doi:10.18632/oncotarget.18864

38. He L, Xu JM, Liu M, Chen ZJ, Li X, Zhu R. Intrathecal dexmedetomidine alleviates shivering during cesarean delivery under spinal anesthesia. Biolog Pharm Bulletin. 2017;40:169.

39. Qi X, Li Y, Rahe MN, et al. Intrathecal dexmedetomidine as adjuvant to ropivacaine in hysteroscopic surgery: a prospective, randomized control study. Inter $J$ Clinic PharmTherap. 2016;54:185. doi:10.5414/CP202427

40. Xiaofei Q, Yuantao L, Niels RM, et al. Comparison of intrathecal dexmedetomidine with morphine as adjuvants in cesarean sections. BiologPharmBulletin. 2016;39:1455.

41. Li Z, Tian M, Zhang CY, et al. A randomised controlled trial to evaluate the effectiveness of intrathecal bupivacaine combined with different adjuvants (fentanyl, clonidine and dexmedetomidine) in caesarean section. Drug Res. 2014;65:581. doi:10.1055/s-00341395614

42. Han C, Jiang X, Wu X, Ding Z. Application of dexmedetomidine combined with ropivacaine in the cesarean section under epidural anesthesia. Zhonghua Yi Xue Za Zhi. 2014;94:3501-3505.

43. Sun Y, Xu Y, Wang GN. Comparative evaluation of intrathecal bupivacaine alone, bupivacaine-fentanyl, and bupivacaine-dexmedetomidine in caesarean section. Drug Res. 2014;65:468-472. doi:10.1055/s-0034-1387740

44. Poupak R, Seyed H, Reza F, Farnad I, Pooya D, Saeed A. Comparative addition of dexmedetomidine and fentanyl to intrathecal bupivacaine in orthopedic procedure in lower limbs. $B M C$ Anesthesiol. 2018;18(1):62. doi:10.1186/s12871-018-0540-6

45. Nasseri K, Ghadami N, Nouri B. Effects of intrathecal dexmedetomidine on shivering after spinal anesthesia for cesarean section: a double-blind randomized clinical trial. Drug Design Develop Therapy. 2017;11:1107. doi:10.2147/DDDT.S131866

46. Gautam B, Niroula S, Sharma M, Lama SM. Effects of intrathecal dexmedetomidine as an adjuvant to hyperbaric bupivacaine for spinal anaesthesia in adults undergoing elective infra-umbilical surgery. JNMA J Nepal Med Assoc. 2017;56:379-387.

47. Moawad HES, Elawdy MM. Efficacy of intrathecal dexmedetomidine in prevention of shivering in patients undergoing transurethral prostatectomy: a randomized controlled trial. Egyp J Anaesth. 2015;31:181-187. doi:10.1016/j.egja.2015.01.001

48. de PCHD, Fim NC, Marques MA, et al. Clinical and histological effects of the intrathecal administration of a single dose of dexmedetomidine in rabbits. Pain Physic. 2016;19:319.

49. Hongx Z, Fang Z, Chen L, et al. Molecular mechanisms underlying the analgesic property of intrathecal dexmedetomidine and its neurotoxicity evaluation: an in vivo and in vitro experimental study. PLoS One. 2013;8:55556. doi:10.1371/journal.pone.0055556

50. Dilek O, Hu D, Ihsan A, Seyhun S, Mine S, Kamil T. Evaluation of the neurotoxicity of intrathecal dexmedetomidine on rat spinal cord. Saudi J Anaesth. 2018;12(1):10. doi:10.4103/sja.SJA 14317

51. Elham M, Mohammad AH, Ali M, et al. Comparison of histopathological effects of perineural administration of bupivacaine and bupivacaine-dexmedetomidine in rat sciatic nerve. Experim Toxicol Pathol. 2016;68:559-564. doi:10.1016/j.etp.2016.09.001

52. Wang Q, Tan Y, Zhang N, et al. Dexmedetomidine inhibits activation of the MAPK pathway and protects PC12 and NG108-15 cells from lidocaine-induced cytotoxicity at its maximum safe dose. Biomed Pharm. 2017;91:162. doi:10.1016/j.biopha.2017.04.084

53. Yang X, Zhang Y, Zhan Y, Liu Z, Xiang M. Application of ropivacaine combineddexmedetomidine is beneficial for rat spinal cord injury. Intern J Clinic Experim Med. 2017;10(1):1080-1086. 
54. Chiao F, Boretsky K. Dexmedetomidine as a supplement to spinal anesthesia block: a case report of three infants. $A \& A$ Case Reports. 2017;9:127-128. doi:10.1213/XAA.0000000000000545

55. Kannojia UK, Meena RK, Paswan AK, Loha S. Comparison of caudal dexmedetomidine and fentanyl combined with bupivacaine in pediatric patients undergoing urogenital surgery. Anaesth PainIntens Care. 2017;21:204-211.

56. Feyzi C, Cüneyt G, Kağan K, et al. The comparison of neuroprotective effects of intrathecal dexmedetomidine and metilprednisolone in spinal cord injury. Intern J Surg. 2013;11:414-418.

57. Tewodros E, David LB, Aman V, et al. Association of off-label drug use and adverse drug events in an adult populationJ. JAMA Intern Med. 2016;176(1):55-63. doi:10.1001/jamainternmed.2015.6058

58. Perez ZJF, Zhu W, Grafe MR, Brambrink AM. Dexmedetomidinemediated neuroprotection against sevoflurane-induced neurotoxicity extends to several brain regions in neonatal rats. Brit $J$ Anaesth. 2017;119:506-516. doi:10.1093/bja/aex222

59. Liu JR, Yuki K, Baek C, Han XH, Soriano SG. Dexmedetomidineinduced neuroapoptosis is dependent on its cumulative dose. Anesth Analg. 2016;123:1008. doi:10.1213/ANE.0000000000001527

60. Hou J, Xia Z, Xiao X, Wan X, Zhao B. Neurotoxicity of intrathecal injections of dexmedetomidine into the rat spinal dorsal horn. Neural Regener Res. 2012;7:1765.

61. Zhang J, Zhang X, Wang H, Zhou H, Tian T, Wu A. Dexmedetomidine as a neuraxial adjuvant for prevention of perioperative shivering: meta-analysis of randomized controlled trials. PLoS One. 2017;12(8):e0183154. doi:10.1371/journal.pone.0183154

62. Zhen XL, Feng YX, Xiao L, et al. Efficacy of dexmedetomidine on postoperative shivering: a meta-analysis of clinical trials. Canad $J$ Anaesth. 2015;62:816-829. doi:10.1007/s12630-015-0368-1

63. Zhang X, Wang D, Shi M, Luo YG. Efficacy and safety of dexmedetomidine as an adjuvant in epidural analgesia and anesthesia: a systematic review and meta-analysis of randomized controlled trials. Clinic Drug Invest. 2016;37:1-12.
64. Huang HW, Hong TW, Jun JJ, et al. Does dexmedetomidine as a neuraxial adjuvant facilitate better anesthesia and analgesia? A systematic review and meta-analysis. PLoS One. 2014;9(3):e93114. doi:10.1371/journal.pone.0093114

65. Abdallah FW, Abrishami A, Brull R. The facilitatory effects of intravenous dexmedetomidine on the duration of spinal anesthesia: a systematic review and meta-analysis. Anesth Analg. 2013;117:271. doi:10.1213/ANE.0b013e318290c566

66. Sun SJ, Wang JM, Bao NR, Ying C, Jun W. Comparison of dexmedetomidine and fentanyl as local anesthetic adjuvants in spinal anesthesia: a systematic review and meta-analysis of randomized controlled trials. Drug Design Develop Therapy. 2017;11:34133424. doi:10.2147/DDDT.S146092

67. Xu B, Li Z, Zhou D, Li L, Li P, Huang H. The influence of age on sensitivity to dexmedetomidine sedation during spinal anesthesia in lower limb orthopedic surgery. Anesth Analg. 2017;125(6):19071910. doi:10.1213/ANE.0000000000002531

68. Abdelghaffar HS, Mohamed AB, Fares KM. Combined intrathecal morphine and dexmedetomidine for postoperative analgesia in patients undergoing major abdominal cancer surgery. Pain Med. 2016;17:2109. doi:10.1093/pm/pnw031

69. Höcker J, Paris A, Scholz J, Tonner PH, Nielsen M, Bein B. Differential effects of $\alpha 2$-adrenoceptors in the modulation of the thermoregulatory response in mice induced by meperidine. Anesthesiology. 2008;109(1):95-100. doi:10.1097/ALN.0b013e318 $17 \mathrm{c} 02 \mathrm{fc}$

70. Zhou C, Zhu Y, Bao Z, Wang XX, Liu Q. Efficacy of ondansetron for spinal anesthesia during cesarean section: a meta-analysis of randomized trials. J Int Med Res. 2018;46(2):654-662. doi:10.1177/ 0300060517716502 


\section{Supplementary material}

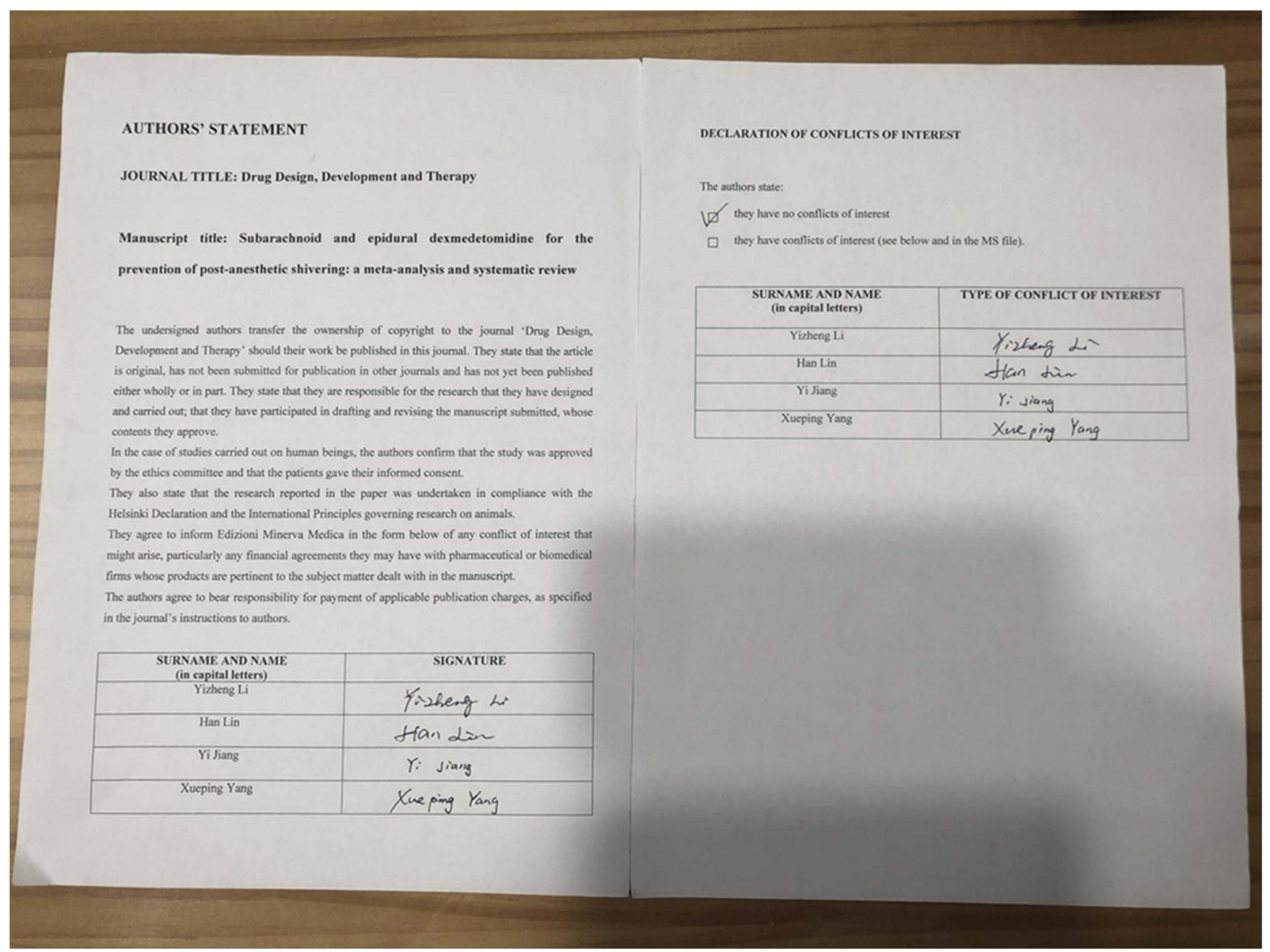

Figure SI Authors' statement.

\section{Publish your work in this journal}

Drug Design, Development and Therapy is an international, peerreviewed open-access journal that spans the spectrum of drug design and development through to clinical applications. Clinical outcomes, patient safety, and programs for the development and effective, safe, and sustained use of medicines are a feature of the journal, which has also been accepted for indexing on PubMed Central. The manuscript management system is completely online and includes a very quick and fair peer-review system, which is all easy to use. Visit http://www. dovepress.com/testimonials.php to read real quotes from published authors. 